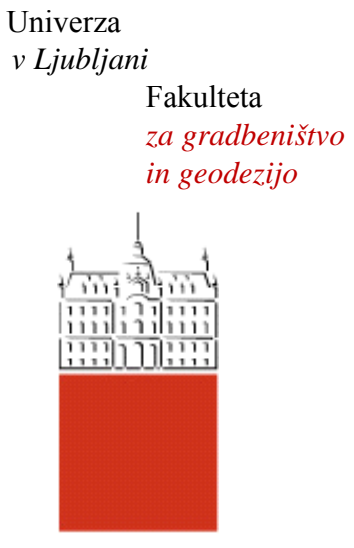

Jamova cesta 2

1000 Ljubljana, Slovenija

http://www3.fgg.uni-lj.si/

\section{DRUGG - Digitalni repozitorij UL FGG http://drugg.fgg.uni-lj.si/}

Ta članek je avtorjeva zadnja recenzirana različica, kot je bila sprejeta po opravljeni recenziji.

Prosimo, da se pri navajanju sklicujte na bibliografske podatke, kot je navedeno:
University
of Ljubljana

Faculty of

Civil and Geodetic

Engineering

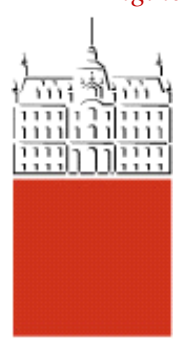

Jamova cesta 2

SI - 1000 Ljubljana, Slovenia

http://www3.fgg.uni-lj.si/en/

DRUGG - The Digital Repository http://drugg.fgg.uni-lj.si/

This version of the article is author's manuscript as accepted for publishing after the review process.

When citing, please refer to the publisher's bibliographic information as follows:

Schnabl, S., Planinc, I. 2011. The effect of transverse shear deformation on the buckling of two-layer composite columns with interlayer slip. International Journal of Non-linear Mechanics 46,3: 543-553 DOI: 10.1016/j.jinonlinmec.2011.01.001. 


\title{
The effect of transverse shear deformation on the buckling of two-layer composite columns with interlayer slip
}

\author{
S. Schnabl* and I. Planinc \\ University of Ljubljana, Faculty of Civil and Geodetic Engineering, Jamova 2, \\ SI-1115 Ljubljana, Slovenia
}

\begin{abstract}
This paper presents an efficient mathematical model for studying the buckling behavior of geometrically perfect elastic two-layer composite columns with interlayer slip between the layers. The present analytical model is based on the linearized stability theory and is capable of predicting exact critical buckling loads. Based on the parametric analysis, the critical buckling loads are compared to those in the literature. It is shown that the discrepancy between the different methods can be up to approximately $22 \%$. In addition, a combined and an individual effect of prebuckling shortening and transverse shear deformation on the critical buckling loads is studied in detail. A comprehensive parametric analysis reveals that generally the effect of pre-buckling shortening can be neglected, while, on the other hand, the effect of transverse shear deformation can be significant. This effect can be up to $20 \%$ for timber composite columns, $40 \%$ for composite columns very flexible in shear (pyrolytic graphite), while for metal composite columns it is insignificant.
\end{abstract}

Keywords: A. Layered structures; B. Interfacial strength; B. Non-linear behaviour; C. Buckling; Interlayer slip 


\section{Introduction}

Engineering structural components made of composite materials are becoming increasingly important in many engineering applications, especially in aerospace, automobile, marine, and civil engineering industry. The driving force behind these applications is a wide range of potential advantages over the conventional structures, such as high strength-to-weight ratio, high stiffnessto-weight ratio, resistance to corrosion, low coefficient of thermal expansion, ability to operate over a wide range of temperatures and their capability for being formed according to a given requirement. In spite of their many attractive qualities, composite structures do, however, often suffer from incomplete interaction between the constituent components. As a result, interlayer slip between the components develops, which can, if it has a sufficient magnitude, significantly affect the mechanical behaviour of the composite system.

Consequently, interlayer slip has to be taken into consideration in what is called partial interaction analysis of composite structures. A considerable amount of research has been conducted on this very interesting topic. Therefore, a large number of references exist in the literature which consider interlayer slip either analytically or numerically, e.g. [1-23].

Design of structures is often based on strength and stiffness considerations. However, the abovementioned composite structures are frequently rather slender and may become unstable long before strength and stiffness criteria are violated. Therefore, stability criterion is very important in structural design,

\footnotetext{
*Corresponding author. Tel.: +38614768 615; Fax: +38614768629

E-mail address: sschnabl@fgg.uni-lj.si (S. Schnabl)
} 
especially when the structure is slender and lightweight. On the other hand, much less literature is available on buckling analysis of composite columns with interlayer slip between the layers, e.g. [6, 11, 22, 24-29]. In all these studies shear deformation effect on critical buckling loads is ignored. In fact, increasingly important composite columns are generally quite shear sensitive because of their low shear modulus to Young's modulus ratio. In this case, the effect of transverse shear deformation can be significant and should be taken into account. While the buckling analysis of solid columns with finite shear stiffness has a long history in engineering science [30-42], only a few papers have dealt with this subject in case of composite columns with interlayer slip between the layers [43-45]. Recent paper by $\mathrm{Xu}$ and $\mathrm{Wu}$ [43] has presented a unique approach of slip-buckling and vibration problem of composite beamcolumns when shear deformation is taken into account. Their formulation is based on what is called second order theory and Engesser's type of buckling approach [41]. Additionally, their formulation is based also on the assumptions of negligible effect of pre-buckling shortening on critical buckling loads and considers the average shear and bending deformation of the cross-section. On the other hand, Krawczyk with co-workers $[44,45]$ has analyzed this problem numerically with finite element method based on a slightly different buckling theory compared to $\mathrm{Xu}$ and $\mathrm{Wu}[43]$.

To complement the aforementioned studies, the main objective of the present paper is to derive an analytical model for slip-buckling problem of composite columns with interlayer slip between the layers where different pre-buckling shortening and transverse shear deformation of each layer are taken into account. For this purpose, in the present formulation each layer is modeled by Reissner's large-displacement finite-strain shear-deformable beam theory [47]. 
In addition, a linearized stability theory is employed [48] by which critical buckling forces of the composite columns with interlayer slip are determined from the solution of a linear eigenvalue problem [49].

In the numerical examples, a comparison between the different approaches is made, followed by a detailed parametric study by which combined and individual effects of pre-buckling shortening and transverse shear deformation on critical buckling load are examined for a wide range of possible material and geometric parameters, such as flexural-to-shear ratios $(E / G)$, interlayer slip modulus $(K)$, column slenderness ratios $(\lambda)$ and different boundary conditions.

Finally, an analytical benchmark solution to the problem of column buckling with interlayer slip considering pre-buckling shortening and transverse shear effects is given. This solution will serve as a tool for the verification of numerical results obtained by different numerical methods.

\section{Governing equations for two-layer composite column}

Considered here is a geometrically perfect initially straight, planar, two-layer composite column of undeformed length $L$. Layers, as shown in Fig. 1, are marked by letters $a$ and $b$. The column is placed in the $(X, Z)$ plane of spatial Cartesian coordinate system with coordinates $(X, Y, Z)$ and unit base vectors $\boldsymbol{E}_{X}, \boldsymbol{E}_{Y}$ and $\boldsymbol{E}_{Z}=\boldsymbol{E}_{X} \times \boldsymbol{E}_{Y}$. The initial undeformed reference axis of the layered column is common to both layers. It is parametrized by the undeformed arc-length $x$. Material particles of each layer are identified by material coordinates $(x, y, z)$ in local coordinate system which are assumed to coincide initially with spatial coordinates, and then they follow the deformation of the 
column. Thus, $x^{a} \equiv x^{b} \equiv x \equiv X, y^{a} \equiv y^{b} \equiv y \equiv Y$, and $z^{a} \equiv z^{b} \equiv z \equiv Z$ in the initial undeformed configuration. The two-layer composite column is loaded longitudinally at the free end by an axial conservative compressive force, $P$, in such a way that homogeneous stress-strain state of the column in its primary configuration is achieved. For further details an interested reader is referred to, e.g. [22, 29].

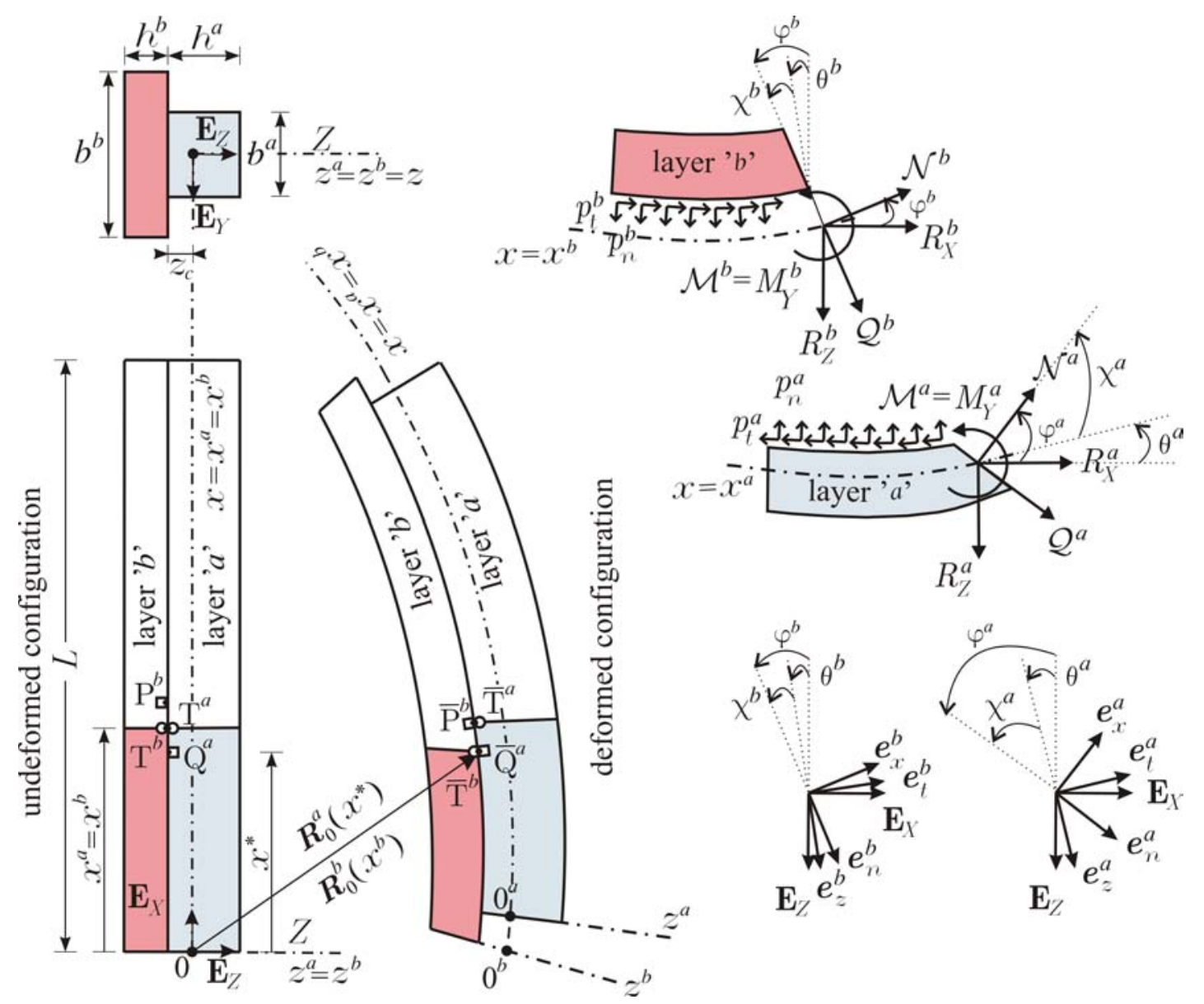

Figure 1. Two-layer composite column. Initial undeformed and current deformed configurations. Generalized equilibrium internal forces and contact tractions. Coordinate systems and their base vectors. 


\subsection{Kinematic equations}

The deformed configurations of the reference axes of layers $a$ and $b$ are defined by vector-valued functions (see Fig. 1)

$$
\begin{aligned}
& \boldsymbol{R}_{0}^{a}=X^{a} \boldsymbol{E}_{X}+Y^{a} \boldsymbol{E}_{Y}+Z^{a} \boldsymbol{E}_{Z}=\left(x+u^{a}\right) \boldsymbol{E}_{X}+y \boldsymbol{E}_{Y}+w^{a} \boldsymbol{E}_{Z}, \\
& \boldsymbol{R}_{0}^{b}=X^{b} \boldsymbol{E}_{X}+Y^{b} \boldsymbol{E}_{Y}+Z^{b} \boldsymbol{E}_{Z}=\left(x+u^{b}\right) \boldsymbol{E}_{X}+y \boldsymbol{E}_{Y}+w^{b} \boldsymbol{E}_{Z},
\end{aligned}
$$

in which superscripts $a$ and $b$ indicate that quantities are related to layers $a$ and $b$, respectively. Functions $u^{a}$ and $w^{a}$ denote the components of the displacement vector of layer $a$ at the reference axis with respect to the base vectors $\mathbf{E}_{X}$ and $\mathbf{E}_{Z}$. Similarly, functions $u^{b}$ and $w^{b}$ are related to layer $b$. The geometrical components $u^{a}, w^{a}, u^{b}$, and $w^{b}$ of the the vector-valued functions $\boldsymbol{R}_{0}^{a}$ and $\boldsymbol{R}_{0}^{b}$ are related to the deformation variables by the following kinematic equations of Reissner's large-displacement finite-strain shear-deformable beam theory, see [47]:

layer $a$ :

$$
\begin{gathered}
1+u^{a \prime}-\left(1+\varepsilon^{a}\right) \cos \varphi^{a}-\gamma^{a} \sin \varphi^{a}=0 \\
w^{a \prime}+\left(1+\varepsilon^{a}\right) \sin \varphi^{a}-\gamma^{a} \cos \varphi^{a}=0 \\
\varphi^{a \prime}-\kappa^{a}=0
\end{gathered}
$$

layer $b$ :

$$
\begin{gathered}
1+u^{b \prime}-\left(1+\varepsilon^{b}\right) \cos \varphi^{b}-\gamma^{b} \sin \varphi^{b}=0 \\
w^{b \prime}+\left(1+\varepsilon^{b}\right) \sin \varphi^{b}-\gamma^{b} \cos \varphi^{b}=0 \\
\varphi^{b \prime}-\kappa^{b}=0 .
\end{gathered}
$$

Here, the prime $\left(^{\prime}\right)$ is used to indicate differentiation with respect to the axial coordinate $x$. In Eqs. (2)-(3), the deformation variables $\varepsilon^{a}$ and $\varepsilon^{b}$ are the axial strains; $\kappa^{a}$ and $\kappa^{b}$ are the pseudocurvatures; $\varphi^{a}$ and $\varphi^{b}$ are the rotations of layers' cross-sections; while $\gamma^{a}$ and $\gamma^{b}$ are the shear strains [46]. 
In addition to Eqs. (2)-(3), Reissner [47] proved that the extensional strains $\varepsilon^{a}$ and $\varepsilon^{b}$ and shear strains $\gamma^{a}$ and $\gamma^{b}$, are related respectively to the corresponding layer's specific axial elongations $e^{a}$ and $e^{b}$ of the reference axis and shearing angles $\chi^{a}=\varphi^{a}-\theta^{a}$ and $\chi^{b}=\varphi^{b}-\theta^{b}$ by means of the following kinematic relations:

$$
\begin{array}{ll}
\varepsilon^{a}=\left(1+e^{a}\right) \cos \chi^{a}-1, & \gamma^{a}=\left(1+e^{a}\right) \sin \chi^{a}, \\
\varepsilon^{b}=\left(1+e^{b}\right) \cos \chi^{b}-1, & \gamma^{b}=\left(1+e^{b}\right) \sin \chi^{b},
\end{array}
$$

where $\theta^{a}$ and $\theta^{b}$ are the rotations of the reference axis of layer $a$ and $b$, respectively, defined by

$$
\theta^{a}=-\arctan \frac{w^{a \prime}}{1+u^{a \prime}}, \quad \theta^{b}=-\arctan \frac{w^{b \prime}}{1+u^{b^{\prime}}} .
$$

It is assumed that the plane of the cross-sections remain plane but not perpendicular to the column reference axis during deformation, i.e. the Timoshenko beam approximation. The material base vectors $\boldsymbol{e}_{t}^{a}, \boldsymbol{e}_{n}^{a}, \boldsymbol{e}_{t}^{b}$, and $\boldsymbol{e}_{n}^{b}$ are assumed to remain orthogonal, see Fig. 1 . The units normals, $\boldsymbol{e}_{x}^{a}$ and $\boldsymbol{e}_{x}^{b}$ to the layers' cross-sectional planes in the deformed state are given by

$$
\begin{aligned}
& \boldsymbol{e}_{x}^{a}=\cos \varphi^{a} \boldsymbol{E}_{X}-\sin \varphi^{a} \boldsymbol{E}_{Z}, \\
& \boldsymbol{e}_{z}^{a}=\sin \varphi^{a} \boldsymbol{E}_{X}+\cos \varphi^{a} \boldsymbol{E}_{Z}, \\
& \boldsymbol{e}_{x}^{b}=\cos \varphi^{b} \boldsymbol{E}_{X}-\sin \varphi^{b} \boldsymbol{E}_{Z}, \\
& \boldsymbol{e}_{z}^{b}=\sin \varphi^{b} \boldsymbol{E}_{X}+\cos \varphi^{b} \boldsymbol{E}_{Z},
\end{aligned}
$$

where $\boldsymbol{e}_{z}^{a}$ and $\boldsymbol{e}_{z}^{b}$ lie in the layers' cross-sectional planes in the deformed state and define the direction of resultant shear forces. The base vectors $\boldsymbol{e}_{x}^{a}, \boldsymbol{e}_{z}^{a}$, $\boldsymbol{e}_{x}^{b}$, and $\boldsymbol{e}_{z}^{b}$ also separately form the orthonormal sets of base vectors of each individual layer. 


\subsection{Equilibrium equations}

The two-layer composite column is subjected only to a conservative compressive force $P=P^{a}+P^{b}$ at the free end, where $P^{a}$ and $P^{b}$ represent axial forces that correspond to the layers $a$ and $b$, respectively. In addition, each layer of the two-layer composite column is subjected to interlayer contact tractions, measured per unit of layer's undeformed length, which are defined by

$$
\begin{aligned}
& \boldsymbol{p}^{a}=p_{X}^{a} \boldsymbol{E}_{X}+p_{Z}^{a} \boldsymbol{E}_{Z}=\left(p_{t}^{a} \cos \theta^{a}+p_{n}^{a} \sin \theta^{a}\right) \boldsymbol{E}_{X}+\left(p_{n}^{a} \cos \theta^{a}-p_{t}^{a} \cos \theta^{a}\right) \boldsymbol{E}_{Z} \\
& \boldsymbol{p}^{b}=p_{X}^{b} \boldsymbol{E}_{X}+p_{Z}^{b} \boldsymbol{E}_{Z}=\left(p_{t}^{b} \cos \theta^{b}+p_{n}^{b} \sin \theta^{b}\right) \boldsymbol{E}_{X}+\left(p_{n}^{b} \cos \theta^{b}-p_{t}^{b} \cos \theta^{b}\right) \boldsymbol{E}_{Z}
\end{aligned}
$$

where $p_{t}^{a}, p_{t}^{b}, p_{n}^{a}$, and $p_{n}^{b}$ are the tangential and normal components of the interlayer contact tractions, see Fig. 1. Therefore, the equilibrium equations of an individual layer are, see e.g. [47]:

layer $a$ :

$$
\begin{aligned}
& R_{X}^{a \prime}+p_{X}^{a}=R_{X}^{a \prime}+p_{t}^{a} \cos \theta^{a}+p_{n}^{a} \sin \theta^{a}=0 \\
& R_{Z}^{a \prime}+p_{Z}^{a}=R_{Z}^{a \prime}-p_{t}^{a} \sin \theta^{a}+p_{n}^{a} \cos \theta^{a}=0 \\
& M_{Y}^{a \prime}-\left(1+\varepsilon^{a}\right) \mathcal{Q}^{a}+\gamma^{a} \mathcal{N}^{a}+m_{Y}^{a}=0
\end{aligned}
$$

layer $b$ :

$$
\begin{aligned}
& R_{X}^{b \prime}+p_{X}^{b}=R_{X}^{b \prime}+p_{t}^{b} \cos \theta^{b}+p_{n}^{b} \sin \theta^{b}=0, \\
& R_{Z}^{b \prime}+p_{Z}^{b}=R_{Z}^{b \prime}-p_{t}^{b} \sin \theta^{b}+p_{n}^{b} \cos \theta^{b}=0, \\
& M_{Y}^{b \prime}-\left(1+\varepsilon^{b}\right) \mathcal{Q}^{b}+\gamma^{b} \mathcal{N}^{b}+m_{Y}^{b}=0,
\end{aligned}
$$


where

$$
\begin{aligned}
& \mathcal{N}^{a}=R_{X}^{a} \cos \varphi^{a}-R_{Z}^{a} \sin \varphi^{a}, \\
& \mathcal{Q}^{a}=R_{X}^{a} \sin \varphi^{a}+R_{Z}^{a} \cos \varphi^{a}, \\
& \mathcal{M}^{a}=M_{Y}^{a}, \\
& \mathcal{N}^{b}=R_{X}^{b} \cos \varphi^{b}-R_{Z}^{b} \sin \varphi^{b}, \\
& \mathcal{Q}^{b}=R_{X}^{b} \sin \varphi^{b}+R_{Z}^{b} \cos \varphi^{b}, \\
& \mathcal{M}^{b}=M_{Y}^{b} .
\end{aligned}
$$

The functions $R_{X}^{a}, R_{Z}^{a}, R_{X}^{b}, R_{Z}^{b}, M_{Y}^{a}$, and $M_{Y}^{b}$ in (10)-(12) represent the generalized equilibrium internal forces of the cross-section of layers $a$ and $b$ with respect to the fixed coordinate basis. On the other hand, $\mathcal{N}^{a}, \mathcal{Q}^{a}, \mathcal{M}^{a}$, $\mathcal{N}^{b}, \mathcal{Q}^{b}$ and, $\mathcal{M}^{a}$ represent the equilibrium axial and shear internal forces and bending moments of the layers' cross-sections with respect to the rotated local coordinate system $\boldsymbol{e}_{x}^{a}, \boldsymbol{e}_{z}^{a}, \boldsymbol{e}_{x}^{b}$, and $\boldsymbol{e}_{z}^{b}$. 


\subsection{Boundary conditions}

Kinematic equations, Eqs. (2)-(3), and equilibrium equations, Eqs. (10)-(11), constitute a system of 12 linear differential equations of the first order with constant coefficients for 24 unknown functions: $u^{a}, u^{b}, w^{a}, w^{b}, \varphi^{a}, \varphi^{b}, \theta^{a}, \theta^{b}$, $R_{X}^{a}, R_{X}^{b}, R_{Z}^{a}, R_{Z}^{b}, M_{Y}^{a}, M_{Y}^{b}, \varepsilon^{a}, \varepsilon^{b}, \kappa^{a}, \kappa^{b}, \gamma^{a}, \gamma^{b}, p_{t}^{a}, p_{t}^{b}, p_{n}^{a}$, and $p_{n}^{b}$. The associated natural and essential boundary conditions are:

$x=0$ :

$$
\begin{aligned}
& r_{1}^{0} R_{X}^{a}(0)+r_{2}^{0} u^{a}(0)=-r_{1}^{0} P^{a}, \\
& r_{3}^{0} R_{X}^{b}(0)+r_{4}^{0} u^{b}(0)=-r_{3}^{0} P^{b}, \\
& r_{5}^{0} R_{Z}^{a}(0)+r_{6}^{0} w^{a}(0)=0, \\
& r_{7}^{0} R_{Z}^{b}(0)+r_{8}^{0} w^{b}(0)=0, \\
& r_{9}^{0} M_{Y}^{a}(0)+r_{10}^{0} \varphi^{a}(0)=+r_{9}^{0}\left(\frac{h^{a}}{2}-z_{c}\right) P^{a}, \\
& r_{11}^{0} M_{Y}^{b}(0)+r_{12}^{0} \varphi^{b}(0)=-r_{11}^{0}\left(\frac{h^{b}}{2}+z_{c}\right) P^{b},
\end{aligned}
$$

$x=L:$

$$
\begin{aligned}
& r_{1}^{L} R_{X}^{a}(L)+r_{2}^{L} u^{a}(L)=-r_{1}^{L} P^{a}, \\
& r_{3}^{L} R_{X}^{b}(L)+r_{4}^{L} u^{b}(L)=-r_{3}^{L} P^{b}, \\
& r_{5}^{L} R_{Z}^{a}(L)+r_{6}^{L} w^{a}(L)=0, \\
& r_{7}^{L} R_{Z}^{b}(L)+r_{8}^{L} w^{b}(L)=0, \\
& r_{9}^{L} M_{Y}^{a}(L)+r_{10}^{L} \varphi^{a}(L)=+r_{9}^{L}\left(\frac{h^{a}}{2}-z_{c}\right) P^{a}, \\
& r_{11}^{L} M_{Y}^{b}(L)+r_{12}^{L} \varphi^{b}(L)=-r_{11}^{L}\left(\frac{h^{b}}{2}+z_{c}\right) P^{b},
\end{aligned}
$$

where $r_{i} \in\{0,1\}$ are parameters that determine different combinations of boundary conditions of the two-layer composite column, where the superscripts " $0 "$ and " $L "$ of $s$ identify its value at $x=0$ and $x=L$, respectively. $P^{a}$ and $P^{b}$ are interrelated in such a way that homogeneous stress-strain state 
of the column is assured. $z_{c}$ is the local coordinate of the contact plane between the layers $a$ and $b$, see Fig. 1 .

\subsection{Additional equations}

Because the number of equations is lower than the number of unknown functions, the additional equations, to the above-quoted system of 12 linear differential equations, are needed to find the solution for all unknown functions.

\subsubsection{Constitutive equations}

To relate the equilibrium internal forces $\mathcal{N}^{a}, \mathcal{Q}^{b}, \mathcal{N}^{a}$, and $\mathcal{Q}^{b}$ and equilibrium internal moments $\mathcal{M}^{a}$ and $\mathcal{M}^{b}$ to a material model, the following set of equations which assure the balance of equilibrium and constitutive cross-sectional forces and bending moments of the composite column are introduced. The well known constitutive equations of linear elastic two-layer composite columns are

$$
\begin{aligned}
& \mathcal{N}^{a}-\mathcal{N}_{C}^{a}\left(x, \varepsilon^{a}, \kappa^{a}\right)=\mathcal{N}^{a}-C_{11}^{a} \varepsilon^{a}-C_{12}^{a} \kappa^{a}=0, \\
& \mathcal{Q}^{a}-\mathcal{Q}_{C}^{a}\left(x, \gamma^{a}\right)=\mathcal{Q}^{a}-C_{33}^{a} \gamma^{a}=0 \\
& \mathcal{M}^{a}-\mathcal{M}_{C}^{a}\left(x, \varepsilon^{a}, \kappa^{a}\right)=\mathcal{M}^{a}-C_{21}^{a} \varepsilon^{a}-C_{22}^{a} \kappa^{a}=0, \\
& \mathcal{N}^{b}-\mathcal{N}_{C}^{b}\left(x, \varepsilon^{b}, \kappa^{b}\right)=\mathcal{N}^{b}-C_{11}^{b} \varepsilon^{b}-C_{12}^{b} \kappa^{b}=0, \\
& \mathcal{Q}^{b}-\mathcal{Q}_{C}^{b}\left(x, \gamma^{b}\right)=\mathcal{Q}^{b}-C_{33}^{b} \gamma^{b}=0 \\
& \mathcal{M}^{b}-\mathcal{M}_{C}^{b}\left(x, \varepsilon^{b}, \kappa^{b}\right)=\mathcal{M}^{b}-C_{21}^{b} \varepsilon^{b}-C_{22}^{b} \kappa^{b}=0,
\end{aligned}
$$

where $\mathcal{N}_{C}^{a}, \mathcal{Q}_{C}^{a}, \mathcal{M}_{C}^{b}, \mathcal{N}_{C}^{b}, \mathcal{Q}_{C}^{b}$, and $\mathcal{M}_{C}^{b}$ are constitutive cross-sectional generalized forces dependent only on deformation variables $\varepsilon^{a}, \gamma^{a}, \kappa^{a}, \varepsilon^{b}, \gamma^{b}$, and $\kappa^{b}$. Material and geometric constants of the cross section are marked by $C_{11}^{a}$, $C_{12}^{a}, \ldots, C_{22}^{b}, \ldots, C_{33}^{b}$; e.g., $C_{11}^{a}=E^{a} A^{a}$, where $A^{a}$ and $E^{a}$ denote the cross- 
sectional area and the elastic modulus of layer $a$, respectively; $C_{12}^{a}=E^{a} S^{a}$ and $C_{22}^{a}=E^{a} I^{a}$, where $S^{a}$ and $I^{a}$ denote the static moment and moment of inertia of layer $a$ with respect to the reference axis of the composite column, respectively; $C_{33}^{a}=k_{y}^{a} A^{a} G^{a}$, where $k_{y}^{a}$ is the shear coefficient of the cross section of the layer. In the case of a rectangular cross section and isotropic material, the shear coefficient is 5/6 [50]; and so forth, see e.g. [20].

In addition to Eqs. (15), a constitutive law of the interface between the layers still has to be introduced. Herein, a linear constitutive law of bond slip between the layers is employed:

$$
p_{t}^{a}=K \Delta,
$$

in which $K$ denotes the slip modulus at the interlayer surface and $\Delta$ denotes the interlayer slip between the layers; $\Delta$ will be presented in the next section.

\subsubsection{Constraining equations}

The layer $a$ of the two-layer composite column under deformation is constrained to follow the deformation of the layer $b$, and vice versa. Since the layers can slip along each other but their transverse separation or penetration is not allowed, the aforementioned fact can be expressed by a kinematic-constraint requirement as follows

$$
\boldsymbol{R}_{0}^{b}\left(T^{b}\right)=\boldsymbol{R}_{0}^{a}\left(Q^{a}\right)
$$

or, written differently

$$
\boldsymbol{R}_{0}^{b}(x)=\boldsymbol{R}_{0}^{a}\left(x^{*}\right)
$$

where $x$ and $x^{*}$ are coordinates of two distinct particles $T^{b}$ and $Q^{a}$ of layers $b$ and $a$ in the undeformed configuration, which are in the deformed configuration in contact, see Fig. 1. Written in a componential form, Eqs. (17) or (18) 
are

$$
\begin{gathered}
x+u^{b}(x)+z_{c} \sin \varphi^{b}(x)=x^{*}+u^{a}\left(x^{*}\right)+z_{c} \sin \varphi^{a}\left(x^{*}\right), \\
w^{b}(x)+z_{c} \cos \varphi^{b}(x)=w^{a}\left(x^{*}\right)+z_{c} \cos \varphi^{a}\left(x^{*}\right) .
\end{gathered}
$$

The slip, $\Delta$, that occurs between the layers $a$ and $b$ can be defined as

$$
\Delta(x)=\int_{x}^{x^{*}}\left(\left(1+\varepsilon^{b}(\xi)+z_{c} \kappa^{b}(\xi)\right) \cos \chi^{b}(\xi)+\gamma^{b}(\xi) \sin \chi\right) \mathrm{d} \xi
$$

Besides the above presented kinematic-constraint requirement (17), a stressconstraint requirement is determined from the third Newton's law, which ensures an equilibrium of the interlayer contact tractions of the particles in contact. This requirement is expressed in the vector-valued function form as

$$
\boldsymbol{p}^{a}(x)+\boldsymbol{p}^{b}(x)=\mathbf{0},
$$

and, by substituting (9) into (21), in componential form as

$$
\begin{aligned}
p_{t}^{a} \cos \theta^{a}+p_{n}^{a} \sin \theta^{a}+p_{t}^{b} \cos \theta^{b}+p_{n}^{b} \sin \theta^{b} & =0, \\
-p_{t}^{a} \sin \theta^{a}+p_{n}^{a} \cos \theta^{a}-p_{t}^{b} \sin \theta^{b}+p_{n}^{b} \cos \theta^{b} & =0 .
\end{aligned}
$$

Therefore, Eqs. (2)-(3), (6), (10)-(12), (15)-(16), (19)-(20), and (22) form a complete basis for a non-linear boundary-value problem of a two-layer composite column. Thus, a complete set of non-linear governing equations consists of 32 equations for 32 unknown functions: $u^{a}, u^{b}, w^{a}, w^{b}, \varphi^{a}, \varphi^{b}, \theta^{a}, \theta^{b}, \varepsilon^{a}, \varepsilon^{b}, \gamma^{a}, \gamma^{b}$, $\kappa^{a}, \kappa^{b}, R_{X}^{a}, R_{X}^{b}, R_{Z}^{a}, R_{Z}^{b}, M_{Y}^{a}, M_{Y}^{b}, \mathcal{N}^{a}, \mathcal{N}^{b}, \mathcal{Q}^{a}, \mathcal{Q}^{b}, \mathcal{M}^{a}, \mathcal{M}^{b}, p_{t}^{a}, p_{t}^{b}, p_{n}^{a}, p_{n}^{b}, \Delta$, and $x^{*}$. 


\section{$3 \quad$ Exact buckling response analysis}

\subsection{Linearized stability equations}

The linearized stability equations for the determination of the critical load of the two-layer composite columns, at the bifurcation point, can be derived by the application of the linearized theory of stability. This theory is based on the ascertainment that the critical bifurcation points of the non-linear system coincide with the critical points of the corresponding linearized system [48]. The application of the linearized stability theory, regarding the existence and uniqueness of the solution of Reissner's elastica, is given by Flajs et al [51].

The aforementioned linearized theory of stability is founded upon the variation of a functional $\mathcal{F}$, here made in the sense of the continuous linear Gateaux operator or directional derivative, defined as follows [52]

$$
\delta \mathcal{F}(\boldsymbol{x}, \delta \boldsymbol{x})=\lim _{\alpha \rightarrow 0} \frac{\mathcal{F}(\boldsymbol{x}+\alpha \delta \boldsymbol{x})-\mathcal{F}(\boldsymbol{x})}{\alpha}=\left.\frac{\mathrm{d}}{\mathrm{d} \alpha}\right|_{\alpha=0} \mathcal{F}(\boldsymbol{x}+\alpha \delta \boldsymbol{x}),
$$

where $\boldsymbol{x}$ and $\delta \boldsymbol{x}$ represent the generalized displacement field and its increment, respectively, and $\alpha$ is an arbitrary small scalar parameter. Accordingly, it is convenient for Eqs. (2)-(3), (6), (10)-(12), (15)-(16), (19)-(20), and (22) to be re-written in compact form as $\mathcal{F}=\left\{\mathcal{F}_{1}, \mathcal{F}_{1}, \ldots, \mathcal{F}_{32}\right\}^{T}$, and their arguments as $\boldsymbol{x}=\left\{u^{a}, u^{b}, w^{a}, w^{b}, \ldots, p_{n}^{a}, p_{n}^{b}, \Delta, x^{*}\right\}^{T}$.

In order to apply linearized equations to the two-layer composite column buckling problem, these equations have to be evaluated at the primary configuration of the column, which is an arbitrary deformed configuration in which the composite column remains straight. 
The primary configuration is then defined as follows

$$
\begin{aligned}
& \varepsilon^{a}=\varepsilon^{b}=-\frac{1}{C_{11}^{a}+C_{11}^{b}} P, \\
& \gamma^{a}=\gamma^{b}=0, \\
& \kappa^{a}=\kappa^{b}=0, \\
& u^{a}=u^{b}=u^{a}(0)-\frac{x}{C_{11}^{a}+C_{11}^{b}} P \\
& w^{a}=w^{b}=0, \\
& \varphi^{a}=\varphi^{b}=0, \\
& \theta^{a}=\theta^{b}=0, \\
& x^{*}=x, \\
& \Delta=0, \\
& R_{X}^{a}=\mathcal{N}^{a}=-\frac{C_{11}^{a}}{C_{11}^{a}+C_{11}^{b}} P, \\
& R_{X}^{b}=\mathcal{N}^{b}=-\frac{C_{11}^{b}}{C_{11}^{a}+C_{11}^{b}} P \\
& R_{Z}^{a}=\mathcal{Q}^{a}=0, \\
& R_{Z}^{b}=\mathcal{Q}^{b}=0, \\
& M_{Y}^{a}=\mathcal{M}^{a}=-\frac{C_{21}^{a}}{C_{11}^{a}+C_{11}^{b}} P, \\
& M_{Y}^{b}=\mathcal{M}^{b}=-\frac{C_{21}^{b}}{C_{11}^{a}+C_{11}^{b}} P, \\
& p_{X}^{a}=p_{t}^{a}=0, \\
& p_{X}^{b}=p_{t}^{b}=0, \\
& p_{Z}^{a}=p_{n}^{a}=0, \\
& p_{Z}^{b}=p_{n}^{b}=0 .
\end{aligned}
$$

The system of Eqs. (2)-(3), (6), (10)-(12), (15)-(16), (19)-(20), and (22) is illconditioned for some special cases. In order to avoid this problem, the following additional relations between the deflections and transverse shear forces of the 
composite column, namely, $w=w^{a}=w^{b}$ and $R_{Z}=R_{Z}^{a}+R_{Z}^{b}$ have to be introduced from (19). Based on these relations and linearization of Eqs. (2)(3), (10)-(16), (19), (20), and (21)-(22), the linearized uncoupled equations of the two-layer composite column, when written at the primary configuration (24), can be derived as:

$$
\begin{aligned}
& \delta \mathcal{F}_{1}=\delta u^{a \prime}-\delta \varepsilon^{a}=0, \\
& \delta \mathcal{F}_{2}=\delta u^{b \prime}-\delta \varepsilon^{b}=0, \\
& \delta \mathcal{F}_{3}=\delta w^{\prime}+(1+\varepsilon) \delta \varphi^{a}-\delta \gamma^{a}=0, \\
& \delta \mathcal{F}_{4}=\delta \varphi^{a \prime}-\delta \kappa^{a}=0, \\
& \delta \mathcal{F}_{5}=\delta \varphi^{b \prime}-\delta \kappa^{b}=0, \\
& \delta \mathcal{F}_{6}=\delta R_{X}^{a \prime}-\delta p_{t}=0, \\
& \delta \mathcal{F}_{7}=\delta R_{X}^{b \prime}+\delta p_{t}=0, \\
& \delta \mathcal{F}_{8}=\delta R_{Z}^{\prime}=0 \\
& \delta \mathcal{F}_{9}=\delta M_{Y}^{a \prime}+R_{X}^{a} \delta w^{\prime}-(1+\varepsilon) \delta R_{Z}^{a}+\delta m_{Y}^{a}=0, \\
& \delta \mathcal{F}_{10}=\delta M_{Y}^{b \prime}+R_{X}^{b} \delta w^{\prime}-(1+\varepsilon) \delta R_{Z}^{b}+\delta m_{Y}^{b}=0, \\
& \delta \mathcal{F}_{11}=\delta R_{X}^{a}-C_{11}^{a} \delta \varepsilon^{a}-C_{12}^{a} \delta \kappa^{a}=0, \\
& \delta \mathcal{F}_{12}=\delta R_{X}^{b}-C_{11}^{b} \delta \varepsilon^{b}-C_{12}^{b} \delta \kappa^{b}=0, \\
& \delta \mathcal{F}_{13}=\delta R_{Z}^{a}+R_{X}^{a} \delta \varphi^{a}-C_{33}^{a} \delta \gamma^{a}=0, \\
& \delta \mathcal{F}_{14}=\delta R_{Z}^{b}+R_{X}^{b} \delta \varphi^{b}-C_{33}^{b} \delta \gamma^{b}=0, \\
& \delta \mathcal{F}_{15}=\delta M_{Y}^{a}-C_{21}^{a} \delta \varepsilon^{a}-C_{22}^{a} \delta \kappa^{a}=0, \\
& \delta \mathcal{F}_{16}=\delta M_{Y}^{b}-C_{21}^{b} \delta \varepsilon^{b}-C_{22}^{b} \delta \kappa^{b}=0, \\
& \delta \mathcal{F}_{17}=\delta \Delta-\delta u^{a}+\delta u^{b}+z_{c}\left(\delta \varphi^{b}-\delta \varphi^{a}\right), \\
& \delta \mathcal{F}_{18}=\delta p_{t}-K \delta \Delta=0, \\
& \delta \mathcal{F}_{19}=\delta x^{*}+\delta u^{a}-\delta u^{b}+z_{c}\left(\delta \varphi^{a}-\delta \varphi^{b}\right)=0, \\
& \delta \mathcal{F}_{20}=\delta \gamma^{b}-\delta \gamma^{a}-(1+\varepsilon)\left(\delta \varphi^{b}-\delta \varphi^{a}\right),
\end{aligned}
$$


where

$$
\begin{gathered}
\delta p_{t}=\delta p_{t}^{a}=-\delta p_{t}^{b} \\
\delta R_{Z}=\delta R_{Z}^{a}+R_{Z}^{b}
\end{gathered}
$$

and

$$
\begin{aligned}
& \varepsilon=-\frac{P}{C_{11}^{a}+C_{11}^{b}}, \\
& R_{X}^{a}=-\frac{C_{11}^{a}}{C_{11}^{a}+C_{11}^{b}} P, \\
& R_{X}^{b}=-\frac{C_{11}^{b}}{C_{11}^{a}+C_{11}^{b}} P .
\end{aligned}
$$

Eqs. (25) constitute a system of 20 linear algebraic-differential equations of the first order with constant coefficients for 20 unknown functions: $\delta u^{a}, \delta u^{b}$, $\delta w, \delta \varphi^{a}, \delta \varphi^{b}, \delta \varepsilon^{a}, \delta \varepsilon^{b}, \delta \gamma^{a}, \delta \gamma^{b}, \delta \kappa^{a}, \delta \kappa^{b}, \delta R_{X}^{a}, \delta R_{X}^{b}, \delta R_{Z}^{a}, \delta R_{Z}^{b}, \delta M_{Y}^{a}, \delta M_{Y}^{b}$, $\delta p_{t}, \delta \Delta$, and $\delta x^{*}$ along with the corresponding natural and essential boundary conditions written in the following general form as:

$x=0$ :

$$
\begin{aligned}
& s_{1}^{0} \delta R_{X}^{a}(0)+s_{2}^{0} \delta u^{a}(0)=0, \\
& s_{3}^{0} \delta R_{X}^{b}(0)+s_{4}^{0} \delta u^{b}(0)=0, \\
& s_{5}^{0} \delta R_{Z}(0)+s_{6}^{0} \delta w(0)=0, \\
& s_{7}^{0} \delta M_{Y}^{a}(0)+s_{8}^{0} \delta \varphi^{a}(0)=0, \\
& s_{9}^{0} \delta M_{Y}^{b}(0)+s_{10}^{0} \delta \varphi^{b}(0)=0,
\end{aligned}
$$

$x=L:$

$$
\begin{gathered}
s_{1}^{L} \delta R_{X}^{a}(L)+s_{2}^{L} \delta u^{a}(L)=0, \\
s_{3}^{L} \delta R_{X}^{b}(L)+s_{4}^{L} \delta u^{b}(L)=0, \\
s_{5}^{L} \delta R_{Z}(L)+s_{6}^{L} \delta w(L)=0, \\
s_{7}^{L} \delta M_{Y}^{a}(L)+s_{8}^{L} \delta \varphi^{a}(L)=0, \\
s_{9}^{L} \delta M_{Y}^{b}(L)+s_{10}^{L} \delta \varphi^{b}(L)=0,
\end{gathered}
$$


where $s_{i} \in\{0,1\}$ are again parameters that determine different combinations of boundary conditions of the two-layer composite column. The superscripts "0" and " $L "$ of $s$ identify its value at $x=0$ and $x=L$, respectively.

\subsection{Exact solution for two-layer column critical buckling load}

The system of linear algebraic-differential equations of the first order with constant coefficients (25) and the corresponding natural and essential boundary conditions (28)-(29) can be written as a homogeneous system of 10 first order linear differential equations in compact form as

$$
\boldsymbol{Y}^{\prime}(x)=\boldsymbol{A} \boldsymbol{Y}(x)
$$

and

$$
\boldsymbol{Y}(0)=\boldsymbol{Y}_{0}
$$

where $\boldsymbol{Y}(x)=\left\{\delta u^{a}(x), \delta u^{b}(x), \delta w(x), \delta \varphi^{a}, \ldots, \delta R_{Z}(x), \delta M_{Y}^{a}(x), \delta M_{Y}^{b}(x)\right\}^{\mathrm{T}}$, $\boldsymbol{Y}(0)=\left\{\delta u^{a}(0), \delta u^{b}(0), \delta w(0), \delta \varphi^{a}(0), \ldots, \delta R_{Z}(0), \delta M_{Y}^{a}(0), \delta M_{Y}^{b}(0)\right\}^{\mathrm{T}}$, and $\boldsymbol{A}$ is a constant real $10 \times 10$ matrix. The exact solution of the linear system (30) together with the initial conditions (31) is given by, see e.g. [53, 54]:

$$
\boldsymbol{Y}(x)=\exp ^{\boldsymbol{A} x} \boldsymbol{Y}_{0}
$$

The unknown integration constants, i.e. the initial values of the generalized equilibrium internal forces and components of the displacement vectors, are determined from the boundary conditions (28)-(29). As a result, a system of ten homogeneous linear algebraic equations for ten unknown constants is obtained, which, expressed in a matrix form, reads

$$
K Y_{0}=\mathbf{0},
$$


where $\boldsymbol{K}$ denotes a tangent matrix. For a non-trivial solution of (33), the determinant of the matrix $\boldsymbol{K}$ should vanish, see e.g. [49]

$$
\operatorname{det} \boldsymbol{K}=0 .
$$

The condition (34) represents a linear eigenvalue problem and its solution, i.e. the lowest eigenvalue corresponds to the smallest critical buckling load, $P_{\text {cr }}$, of the column. The explicit form of the matrix $\boldsymbol{K}$ and the analytical solution for the lowest buckling load, $P_{\mathrm{cr}}$, can easily be determined, but they are unfortunately too cumbersome to be presented as closed-form expressions. For further details on the determination of critical points and their classification an interested reader is referred to [49].

\section{Parametric study and discussion}

The analytical procedure for critical buckling loads of geometrically perfect shear-deformable two-layer composite columns with interlayer slip presented in this paper will be numerically evaluated through the analysis of two examples. The first example will be introduced to make a comparison of critical buckling loads with existing buckling loads obtained by other investigators, e.g. [43] and [44, 45]. The second is devoted to the effect of the shear deformation and pre-buckling shortening on the critical buckling loads of two-layer composite columns. In both numerical examples, the critical buckling loads will be computed for a wide range of material and geometric parameters, such as flexural-to-shear ratios $(E / G)$, interlayer slip modulus $(K)$, column slenderness ratios $(\lambda)$, and different boundary conditions given in Table 1 . 
Table 1

Two-layer composite column boundary conditions, effective length coefficients $\beta_{E}$, and buckled shapes of Euler columns.

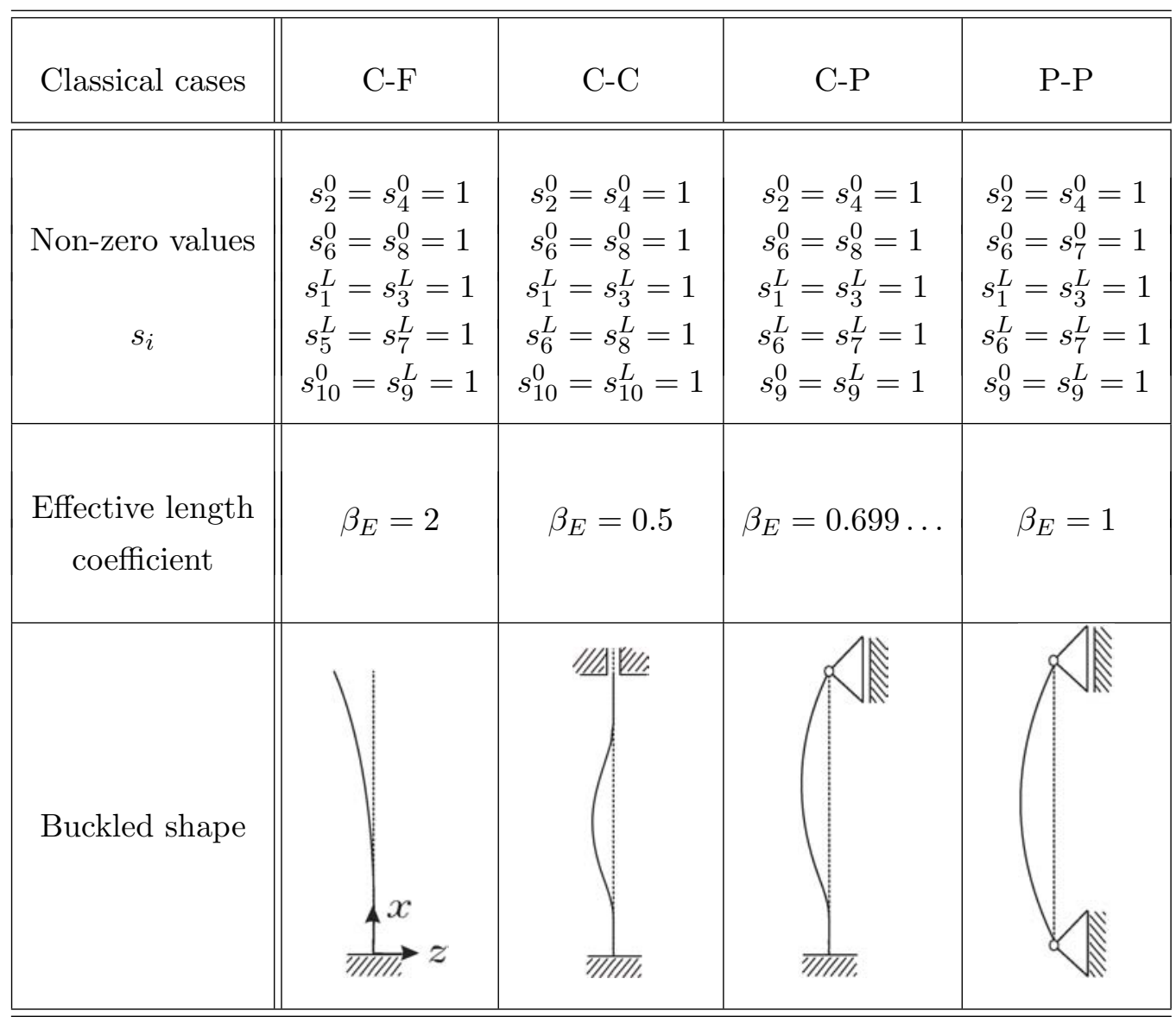

$\mathrm{C}=$ clamped (fixed); $\mathrm{F}=$ free $; \mathrm{P}=$ pinned

4.1 Comparison of critical buckling loads with existing buckling loads in the literature

With the intention of comparing the critical buckling loads of the present analytical model to the above-mentioned buckling models, a timber-concrete composite column is employed. This column has also been studied by other researchers, see, e.g. [1, 3, 22, 25], and [43].

Consecutively, the geometrical and mechanical properties of the timber-concrete 
composite column used in the analysis are presented in Fig. 2.

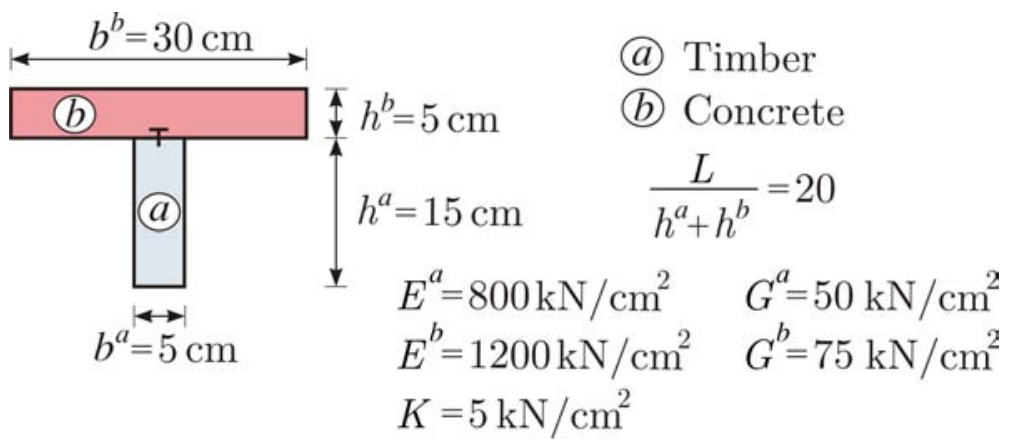

Figure 2. Geometrical and mechanical properties of timber-concrete column.

The critical buckling loads of the two-layer shear-deformable timber-concrete composite column were computed by the proposed analytical model, as a function of interlayer stiffness, $K$, and compared with the results obtained with what is called "second-order theory" proposed by $\mathrm{Xu}$ and $\mathrm{Wu}$ [43]. A comparison is made for boundary conditions used by Girhammar and co-workers [24, 25] and $\mathrm{Xu}$ and $\mathrm{Wu}[43]$ for four different sets of boundary conditions: clamped-free column (C-F), clamped-clamped column (C-C), clamped-pinned column (C-P) and pinned-pinned column (P-P). In accordance to the boundary conditions (28)-(29), the classical boundary conditions of the two-layer Euler columns and the corresponding non-zero values of parameters $s_{i}$ and effective length coefficient, $\beta_{E}$, are summarized in Table 1.

The results are presented and compared in Table 2 for P-P composite column and various interlayer slip moduli $K$. The results indicate that an increase of the interlayer stiffness, $K$, leads to a significant increase of the critical buckling load, $P_{\text {cr }}$. Besides, the present critical buckling loads are identical to those obtained by $\mathrm{Xu}$ and $\mathrm{Wu}$ [43] only when the effects of axial and transverse shear deformations on critical buckling loads are neglected. In all other cases 
the difference between the results is interlayer slip modulus, $K$, dependent. Thus, it can be seen that the difference between the methods increases in magnitude as $K$ increases. It is, however, clear that the difference can be neglected if only axial deformation is taken into account, while it is significant when the influence of transverse shear deformation is taken into consideration. For example, it is interesting to note that in this case the critical buckling load calculated by the present method is in the limiting case when there is an absolutely stiff connection $(\Delta=0 ; K \rightarrow \infty)$, by up to approximately $3.6 \%$ smaller than that calculated by $\mathrm{Xu}$ and $\mathrm{Wu}[43]$.

Table 2

Comparison of the proposed critical buckling loads of P-P two-layer composite column with those of [43] for various $K \mathrm{~s}$.

\begin{tabular}{|c|c|c|c|c|c|c|}
\hline \multicolumn{7}{|c|}{$P_{\mathrm{cr}}[\mathrm{kN}]$} \\
\hline$K$ & $\mathrm{Xu}[43]$ & $\mathrm{Xu}[43]$ & present & present & present & present \\
\hline$\left[\mathrm{kN} / \mathrm{cm}^{2}\right]$ & $\gamma=0$ & $\gamma \neq 0$ & $\varepsilon_{\mathrm{cr}}=0, \gamma=0$ & $\varepsilon_{\mathrm{cr}} \neq 0, \gamma=0$ & $\varepsilon_{\mathrm{cr}}=0, \gamma \neq 0$ & $\varepsilon_{\mathrm{cr}} \neq 0, \gamma \neq 0$ \\
\hline $10^{-10}$ & 92.527541 & 91.847666 & 92.527541 & 92.563241 & 90.974109 & 91.007474 \\
\hline $10^{-5}$ & 92.528541 & 91.848651 & 92.528541 & 92.564242 & 90.977010 & 91.008441 \\
\hline $10^{-3}$ & 92.627505 & 91.946165 & 92.627505 & 92.663282 & 91.070755 & 91.104189 \\
\hline $10^{-2}$ & 93.523952 & 92.829409 & 93.523952 & 93.560425 & 91.937288 & 91.971351 \\
\hline $10^{-1}$ & 102.17982 & 101.35133 & 102.17982 & 102.22336 & 100.29005 & 100.33047 \\
\hline 1 & 166.04327 & 163.86655 & 166.04327 & 166.15831 & 161.13299 & 161.23501 \\
\hline $10^{1}$ & 309.79930 & 302.30694 & 309.79930 & 310.20023 & 293.29511 & 293.61702 \\
\hline $10^{2}$ & 362.61306 & 352.39054 & 362.61306 & 363.16259 & 340.28218 & 340.70797 \\
\hline $10^{3}$ & 369.34178 & 358.74190 & 369.34178 & 369.91192 & 346.21087 & 346.65065 \\
\hline $10^{5}$ & 370.10246 & 359.45951 & 370.10246 & 370.67496 & 346.88032 & 347.32168 \\
\hline $10^{10}$ & 370.11016 & 359.46678 & 370.11016 & 370.68269 & 346.88709 & 347.32847 \\
\hline
\end{tabular}


It should be noted, however, that the formulation used in this paper is based on the energetically consistent formulation of Reissner [31, 47] and Haringx [42]. On the other hand, the only available analytical solution [43] which is used here for comparison is based on Engesser's type of buckling approach [41]. A matter of argument of using Engesser's and Haringx's approach has been the subject of several polemics in the past, see e.g. $[30,31,34,36$ 40]. Moreover, in [43] an average rotation and transverse shear deformation of the composite cross-section is used, while in the present study each layer can have different rotation and shear deformation. Consequently, the abovementioned differences in the two approaches are definitely the main reasons for the discrepancy between the results.

In the sequel, the influence of boundary conditions on the discrepancy of the critical buckling loads of composite columns obtained by the two methods will be studied for other types of boundary conditions presented in Table 1.

This effect may be analyzed by defining a relative error which was here defined as

$$
\varepsilon_{r}[\%]=\frac{P_{\mathrm{cr}}\left(\varepsilon_{\mathrm{cr}}=0, \gamma \neq 0\right)-P_{\mathrm{cr}}^{[43]}}{P_{\mathrm{cr}}\left(\varepsilon_{\mathrm{cr}}=0, \gamma \neq 0\right)} \times 100,
$$

where $P_{\mathrm{cr}}\left(\varepsilon_{\mathrm{cr}}=0, \gamma \neq 0\right)$ and $P_{\mathrm{cr}}^{[43]}$ represent the critical forces obtained by the proposed analytical procedure, where axial deformability is not taken into account, and by $\mathrm{Xu}$ and $\mathrm{Wu}$ [43], respectively. The results for various interlayer slip moduli $K$ are given in Fig. 3. Again, it can be observed in Fig. 3 that increasing interlayer slip modulus $K$ increases the discrepancy between the results for all types of boundary conditions. It is perhaps of interest to note that for the four cases of boundary conditions the discrepancy is the largest for $\mathrm{C}-\mathrm{C}$ column. In this case the difference is considerable and can be up to 
approximately $12 \%$ for very stiff connections between the layers.

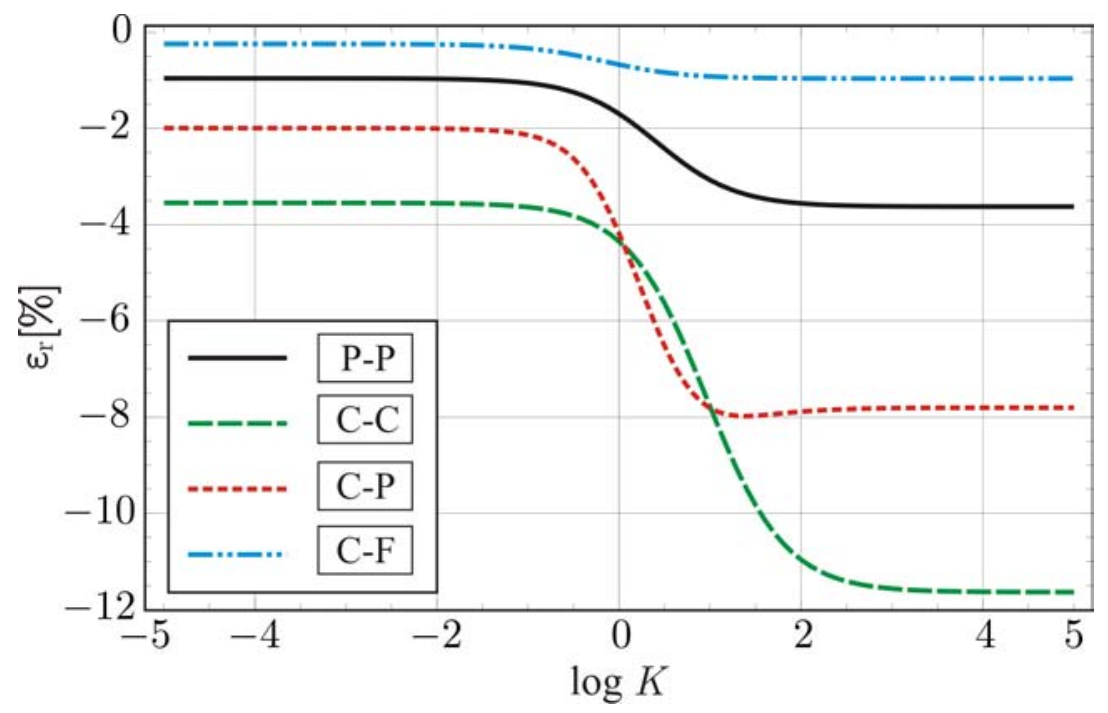

Figure 3. Comparison of the present critical buckling loads with those proposed by $\mathrm{Xu}$ and $\mathrm{Wu}[43]$ for $E / G=16$, different types of boundary conditions and various values of $K$; where $K\left[\mathrm{kN} / \mathrm{cm}^{2}\right]$.

Furthermore, the discrepancy between the methods under consideration is investigated for various $E / G=E^{a} / G^{a}=E^{b} / G^{b}$ and different interlayer slip moduli $K$. Here, only the results for columns with $E / G=2.68$ (ratio typical for isotropic materials such as steel, aluminium, and copper), columns with $E / G=8.67$ (transversely isotropic glass-fiber-reinforced unidirectional composite columns), for anisotropic wood columns with $E / G=16$, and columns with $E / G=50$ are presented for C-C column boundary condition in Fig. 4. As expected, the difference between the methods increases with the increasing interlayer stiffness modulus $K$ and ratio $E / G$. For example, the difference for values of interlayer slip modulus, $K$, which usually exists in actual practice (e.g. $K=10 \mathrm{kN} / \mathrm{cm}^{2}$ ), is for $E / G=2.68,8.67,16$, and 50 up to approximately $1.7 \%, 4.5 \%, 7.5 \%$, and $17.5 \%$, respectively. It is apparent that the difference is even more pronounced for higher interlayer slip moduli $K$. For instance, in the case of wood composite column $(E / G=16)$ and stiff connection the dif- 


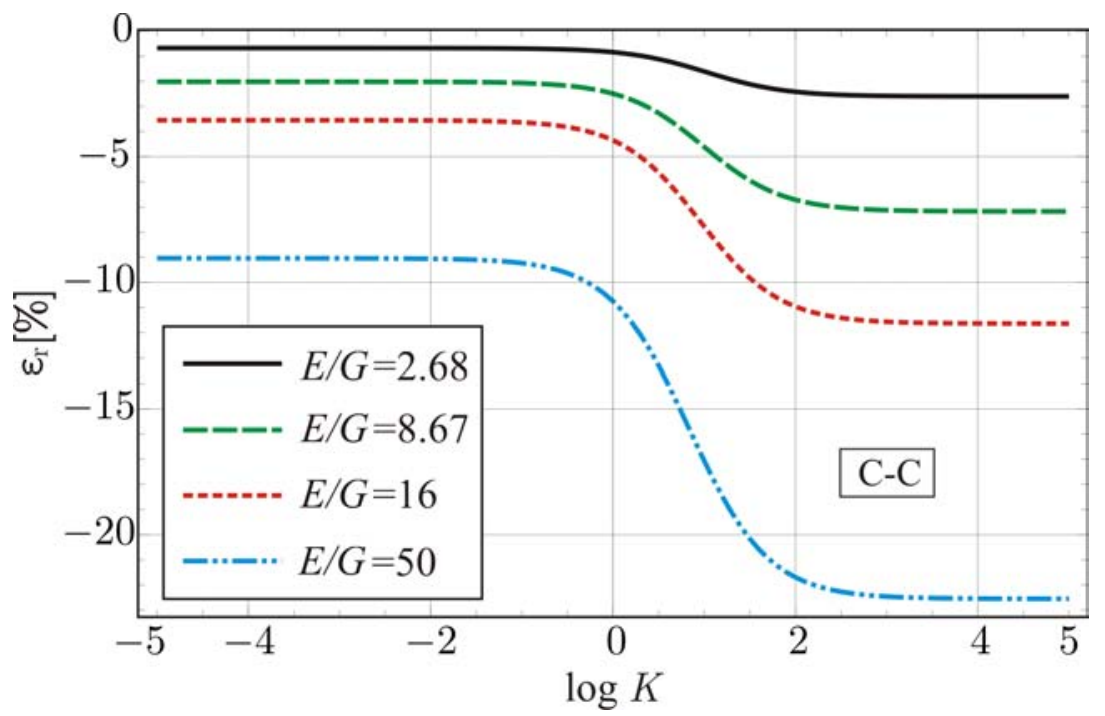

Figure 4. Comparison of the present critical buckling loads with those proposed by $\mathrm{Xu}$ and $\mathrm{Wu}$ [43] for $\mathrm{C}-\mathrm{C}$ column case, different flexural-to-shear ratios, $E / G$, and various values of $K$; where $K\left[\mathrm{kN} / \mathrm{cm}^{2}\right]$.

ference between the results of the two methods compared can be up to $12.5 \%$, while, on the other hand, the difference in case of steel or copper composite columns $(E / G=2.68)$ is less significant.

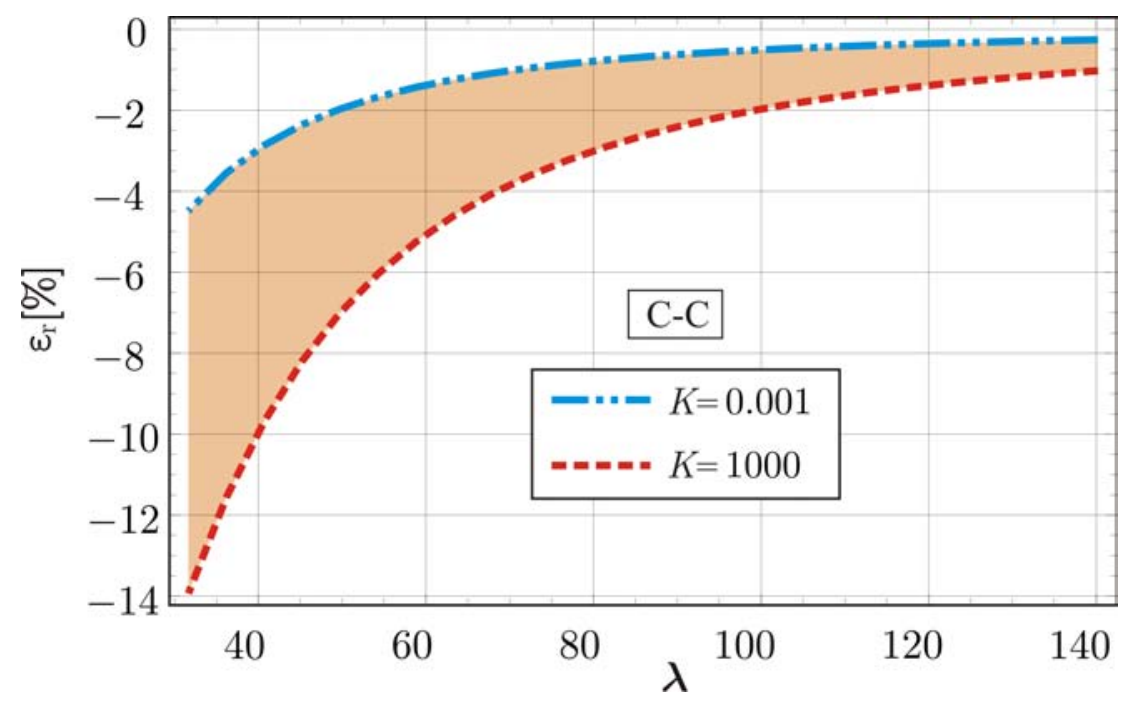

Figure 5. Comparison of the present critical buckling loads with those proposed by $\mathrm{Xu}$ and $\mathrm{Wu}[43]$ for $\mathrm{C}-\mathrm{C}$ column case, different column slenderness ratios, $\lambda$, and various values of $K$; where $K\left[\mathrm{kN} / \mathrm{cm}^{2}\right]$. 
In addition, the difference between the two approaches is investigated for different column slenderness ratios, $\lambda$. In Fig. 5, a relative error defined by Eq. (35) is shown for C-C column as a function of $\lambda$ for two almost limiting cases of interlayer connection, i.e. almost absolutely stiff connection $(K=1000$ $\left.\mathrm{kN} / \mathrm{cm}^{2}\right)$ and no connection between the layers $\left(K=0.001 \mathrm{kN} / \mathrm{cm}^{2}\right)$. Fig. 5 shows that the difference between the methods increases steadily as the slenderness ratio decreases. It can be seen that for very stocky timber composite columns (i.e. $\lambda \approx 35$ ) the difference varies from around $4 \%$ for a very flexible connection to about $14 \%$ for a very stiff connection between the layers. On the other hand, the results of both methods converge to each other for slender composite columns. The difference, however, may become much less pronounced for slender columns with $\lambda>140$.

In what follows, the present analytical results will be compared to, as far as the authors' knowledge is concerned, the only in the open literature available numerical solution for critical buckling loads of composite columns with interlayer slip. This solution is obtained numerically in [45] by using a finite element method. The numerical example under consideration is the same as in our example, except the different elastic shear moduli are used: for wood (the bottom layer $\equiv$ layer $a$ ) a flexural-to-shear ratio, $E^{a} / G^{a}=20$, while for concrete (top layer $\equiv$ layer $b$ ) elastic shear modulus $G^{b}=500 \mathrm{kN} / \mathrm{cm}^{2}$. A uniform finite element mesh of 20 elements is used. The results are the following: $P_{\mathrm{cr}}\left(\varepsilon_{\mathrm{cr}}=0, \gamma \neq 0\right)=255.83 \mathrm{kN} ; P_{\mathrm{cr}}\left(\varepsilon_{\mathrm{cr}} \neq 0, \gamma \neq 0\right)=256.08 \mathrm{kN}$ $P_{\mathrm{cr}}^{\mathrm{FEM}[45]}=257.9 \mathrm{kN}$; and $P_{\mathrm{cr}}^{[43]}=269.89 \mathrm{kN}$. From these results it can be concluded that the buckling loads obtained by the numerical procedure presented in $[44,45]$ almost agree with the present analytical buckling loads, while, on the other hand, for the results proposed by [43] this is not the case. 


\subsection{Investigation of the effect of shear deformation on the critical buckling loads}

In this example, parametric studies are undertaken to investigate the effect of transverse shear deformation on critical buckling loads of two-layer composite columns with interlayer slip between the layers. To this end, a shear deformable two-layer composite column with the same geometric and material parameters as in the first example is used. The critical buckling loads are calculated first for various interlayer moduli $K$ and different boundary conditions. The effect of pre-buckling shortening is neglected. The results are plotted in Fig. 6, where $\varepsilon_{r}^{*}$ is a relative error defined here as

$$
\varepsilon_{r}^{*}[\%]=\frac{P_{\mathrm{cr}}\left(\varepsilon_{\mathrm{cr}}=0, \gamma \neq 0\right)-P_{\mathrm{cr}}\left(\varepsilon_{\mathrm{cr}}=0, \gamma=0\right)}{P_{\mathrm{cr}}\left(\varepsilon_{\mathrm{cr}}=0, \gamma \neq 0\right)} \times 100
$$

In Eq. (36), the critical forces are obtained by the consistent composite-column boundary conditions given in [22].

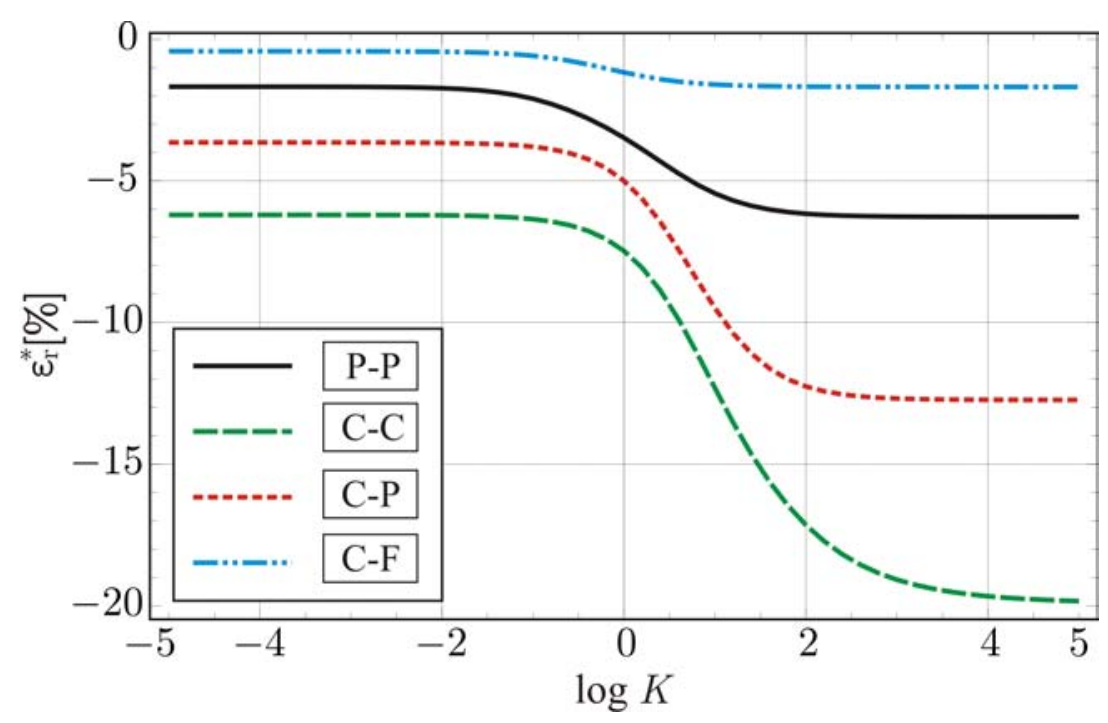

Figure 6. The effect of transverse shear deformation on critical buckling loads of geometrically perfect two-layer composite column with $E / G=16$ for various values of $K$ and different types of boundary conditions; where $K\left[\mathrm{kN} / \mathrm{cm}^{2}\right]$. 
It is apparent from Fig. 6 that critical buckling loads decrease if shear deformation is taken into account. It can also be seen from Fig. 6 that the effect of shear deformation on the critical buckling loads increases in magnitude as the column end conditions vary from $\mathrm{C}-\mathrm{F}$ to $\mathrm{C}-\mathrm{C}$ case and as the interlayer modulus, $K$, increases. For example, it is interesting to note that for a practical value of interlayer slip modulus $K=10 \mathrm{kN} / \mathrm{cm}^{2}(\log K=1)$, the corresponding relative errors are: $\varepsilon_{r}^{*}[\mathrm{C}-\mathrm{F}]=-1.60 \%, \varepsilon_{r}^{*}[\mathrm{P}-\mathrm{P}]=-5.88 \%, \varepsilon_{r}^{*}[\mathrm{C}-$ $\mathrm{P}]=-9.49 \%, \varepsilon_{r}^{*}[\mathrm{C}-\mathrm{C}]=-12.32 \%$, while, in the two limiting cases, when there is no connection $(\Delta \neq 0 ; K \rightarrow 0): \varepsilon_{r}^{*}[\mathrm{C}-\mathrm{F}]=-0.43 \%, \varepsilon_{r}^{*}[\mathrm{P}-\mathrm{P}]=-1.68 \%, \varepsilon_{r}^{*}[\mathrm{C}-$ $\mathrm{P}]=-3.65 \%, \varepsilon_{r}^{*}[\mathrm{C}-\mathrm{C}]=-6.20 \%$, or there is an absolutely stiff connection between the layers $(\Delta=0 ; K \rightarrow \infty), \varepsilon_{r}^{*}[\mathrm{C}-\mathrm{F}]=-1.69 \%, \varepsilon_{r}^{*}[\mathrm{P}-\mathrm{P}]=-6.28 \%$, $\varepsilon_{r}^{*}[\mathrm{C}-\mathrm{P}]=-12.74 \%, \varepsilon_{r}^{*}[\mathrm{C}-\mathrm{C}]=-19.84 \%$. Evidently, the effect of transverse shear deformation on the critical buckling loads is negligible in C-F and P-P column cases and in all other cases when there exists a partial interaction between the layers with $K<0.1 \mathrm{kN} / \mathrm{cm}^{2}(\log K=-1)$.

Besides, some parametric studies are performed next to investigate the effect of shear deformation for various material properties, i.e. flexural-to-shear ratios $(E / G)$, interlayer slip modulus $(K)$, and column slenderness ratios $(\lambda)$. In Fig. 7, a relative error, $\varepsilon_{r}^{*}$, is shown for C-C column as a function of interlayer slip modulus, $K$, for different flexural-to-shear ratios. It can be observed in Fig. 7 that increasing the interlayer stiffness increases the effect of shear deformation on critical buckling loads for all the flexural-to-shear ratios. This effect is considerable for composite columns with $E / G \geq 16$. Moreover, the effect is also pronounced for materials with $E / G=8.67$ if interlayer modulus $K>10$ $\mathrm{kN} / \mathrm{cm}^{2}$. In this case $\varepsilon_{r}^{*}$ ranges from $-7.27 \%$ for $K=10 \mathrm{kN} / \mathrm{cm}^{2}$ to $-12.27 \%$ for a stiff connection between the layers. This suggests that for purposes of, e.g. 
C-C composite column design, the effect of shear deformation on the buckling loading is found to be considerable and should be taken into account when

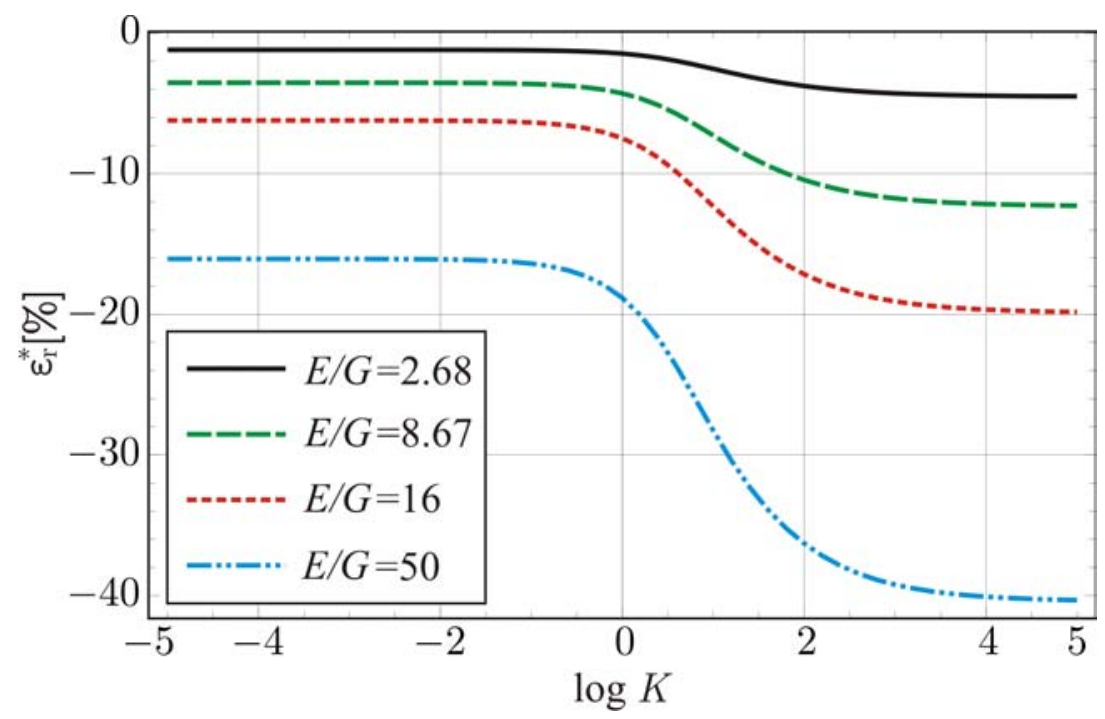

Figure 7. The effect of transverse shear deformation on critical buckling loads of geometrically perfect two-layer C-C composite column for various flexural-to-shear ratios $E / G$ and different values of $K$; where $K\left[\mathrm{kN} / \mathrm{cm}^{2}\right]$.

$E / G \geq 16$ or $E / G \geq 8.67$ and $K>10 \mathrm{kN} / \mathrm{cm}^{2}$.

Additionally, the effect of transverse shear deformability on the critical buckling load, $P_{\text {cr }}$, of the geometrically perfect two-layer composite columns with interlayer slip between the layers is analyzed for various interlayer slip moduli $K$ and for different column slenderness ratios $\lambda$ which are defined here as

$$
\lambda=\frac{\beta_{E} L \sqrt{A^{a}+A^{b}}}{\sqrt{I^{a}+I^{b}}},
$$

where $\beta_{E}$ represents the effective length coefficient of Euler columns with stiff connection between the layers. Effective length coefficients, $\beta_{E}$, are given in Table 1 for different types of end conditions along with schematic illustrations of the buckling modes. Variation in column slenderness is achieved by considering a range of column lengths. 
The results for timber C-C composite column and $0.001 \mathrm{kN} / \mathrm{cm}^{2} \leq K \leq$ $1000 \mathrm{kN} / \mathrm{cm}^{2}$ are given in Fig. 8. As would be expected, Fig. 8 indicates that the transverse shear effect becomes important for short (stocky) columns with low values of $\lambda$ (for $\lambda$ up to 60) and high values of $K$. For example, the critical load predicted by the present theory is for the values of $\lambda=40$ and $K=1000 \mathrm{kN} / \mathrm{cm}^{2}$ about $16.5 \%$ lower than that predicted without transverse shear effects. On the other hand, this effect may become much less pronounced for slender columns $(\lambda>60)$. In the latter case it may be neglected. As would

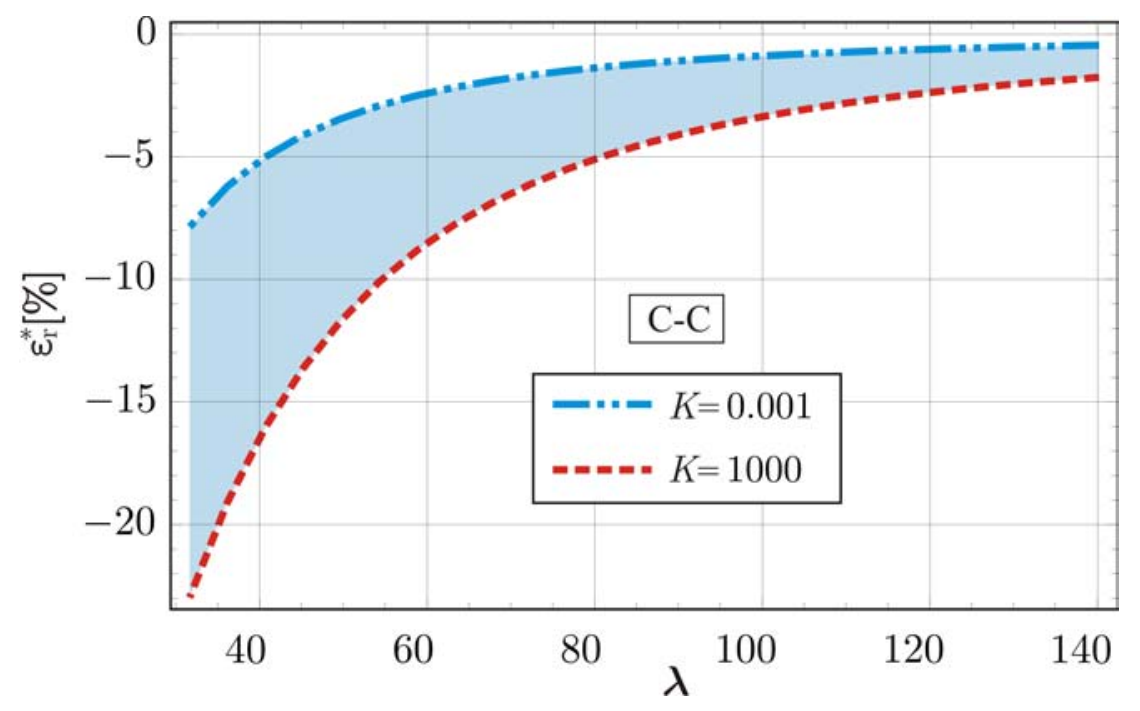

Figure 8. The effect of transverse shear deformation on critical buckling loads of geometrically perfect two-layer C-C timber $(E / G=16)$ composite column for various column slenderness ratios $\lambda$ and different values of $K$; where $K\left[\mathrm{kN} / \mathrm{cm}^{2}\right]$.

be expected, the shear deformation effect is very important in the buckling analysis of composite columns only in the range of low slenderness ratios.

Finally, with the intention of comparing the results, the critical buckling loads of C-C timber composite column are given in Table 3 as an analytic benchmark solution to the problem of column buckling considering pre-buckling shortening and transverse shear effects. Once again, it is interesting to note, that 
transverse shear deformation has a significant influence on the critical buckling loads, while, one the other hand, the effect of pre-buckling shortening can be neglected.

Table 3

A benchmark solution to the composite column buckling considering pre-buckling shortening and transverse shear effects. The critical buckling loads of C-C two-layer composite column for $E / G=16$ and various $K$ s.

\begin{tabular}{ccccc}
\hline \hline \multicolumn{5}{c}{$P_{\mathrm{cr}}[\mathrm{kN}]$} \\
\hline$K$ & present & present & present & present \\
{$\left[\mathrm{kN} / \mathrm{cm}^{2}\right]$} & $\varepsilon_{\mathrm{cr}}=0, \gamma=0$ & $\varepsilon_{\mathrm{cr}} \neq 0, \gamma=0$ & $\varepsilon_{\mathrm{cr}}=0, \gamma \neq 0$ & $\varepsilon_{\mathrm{cr}} \neq 0, \gamma \neq 0$ \\
\hline $10^{-10}$ & 370.11016 & 370.68268 & 347.14812 & 347.59158 \\
$10^{-5}$ & 370.11116 & 370.68369 & 347.14900 & 347.59247 \\
$10^{-3}$ & 370.21013 & 370.78297 & 347.23622 & 347.67989 \\
$10^{-2}$ & 371.10748 & 371.68310 & 348.02684 & 348.47241 \\
$10^{-1}$ & 379.86233 & 380.46547 & 355.72859 & 356.19280 \\
1 & 454.14727 & 455.00991 & 420.20327 & 420.83582 \\
$10^{1}$ & 802.20158 & 804.90102 & 703.39131 & 704.98306 \\
$10^{2}$ & 1216.9577 & 1223.1919 & 1008.2466 & 1011.1567 \\
$10^{3}$ & 1399.2669 & 1407.5215 & 1132.2687 & 1135.7586 \\
$10^{5}$ & 1472.9002 & 1482.0522 & 1180.7485 & 1184.4673 \\
$10^{10}$ & 1480.4406 & 1489.6871 & 1337.3584 & 1343.5515 \\
\hline \hline
\end{tabular}

\section{Conclusions}

The paper presents an efficient mathematical model for studying the buckling behavior of geometrically perfect two-layer composite columns with inter- 
layer slip between the layers. The model is capable of predicting exact critical buckling loads. The result have been compared with the solutions from the literature. Likewise, the effects of pre-buckling shortening and transverse shear deformation on the critical buckling loads have been studied. From the present study, the following conclusions can be drawn:

(1) It is shown that the critical buckling loads obtained by the present analytical model are identical to those obtained by what is called the "secondorder theory" proposed by Xu and Wu [43] only if the effects of transverse shear deformation and pre-buckling shortening on critical buckling loads are neglected. On the other hand, if these effects are taken into consideration, a significant discrepancy between the critical buckling loads is obtained. This discrepancy has been proved to be interlayer-slip modulus, flexural-to-shear ratios, column slenderness ratios, and boundary conditions dependent.

(2) In is observed that the difference between the methods increases with the increasing of interlayer slip modulus, $K$, and flexural-to-shear ratios, $E / G$, for all types of boundary conditions. The difference is always the largest for $\mathrm{C}-\mathrm{C}$ composite column. In this case it is considerable and it is in case of a very stiff connection between the layers up to approximately $2.6 \%, 7.2 \%, 12 \%, 22 \%$ for $E / G=2.68,8.67,16$, and 50 , respectively.

(3) As anticipated, the effect of pre-buckling shortening on the critical buckling loads of composite columns with interlayer slip can be neglected. On the other hand, the effect of transverse shear deformation is proved to be significant and interlayer-slip modulus, flexural-to-shear ratios, column slenderness ratios, and boundary conditions dependent.

(4) As expected, the critical buckling loads decrease if transverse shear defor- 
mation is taken into account. The inclusion of pre-buckling shortening has the opposite effect. The latter effect is proved to be insignificant in most cases. It is also seen that the effect of shear deformation on the critical buckling loads increases in magnitude as the column end conditions vary from C-F to C-C case and as the interlayer modulus, $K$, and flexuralto-shear ratios, $E / G$, increase. In case of timber composite columns with $E / G=16$, this effect could be for C-F, P-P, C-P, and C-C column from up to approximately $0.43 \%, 1.68 \%, 3.65 \%$, and $6.20 \%$ for very flexible connections to about $1.69 \%, 6.28 \%, 12.74 \%$, and $19.84 \%$ for very stiff connections between the layers, respectively. It is also observed that the effect of transverse shear is considerable for C-C composite columns with $E / G \geq 16$. Moreover, the effect is also pronounced for materials with $E / G=8.67$ if interlayer modulus $K>10 \mathrm{kN} / \mathrm{cm}^{2}$. In this case, the difference ranges from $7.27 \%$ for $K=10 \mathrm{kN} / \mathrm{cm}^{2}$ to $12.27 \%$ for a stiff connection between the layers. This suggests, that for purposes of C-C composite column design, the effect of shear deformation on the buckling loading should be taken into account when $E / G \geq 16$ or $E / G \geq 8.67$ and $K>10 \mathrm{kN} / \mathrm{cm}^{2}$. Additionally, it is shown that the transverse shear effect becomes important for short (stocky) columns with low values of $\lambda$ (for $\lambda$ up to 60) and high values of $K$. For example, the critical load predicted by the present theory is for the values of $\lambda=40$ and $K=1000 \mathrm{kN} / \mathrm{cm}^{2}$ about $16.5 \%$ lower than that predicted without transverse shear effects. On the other hand, this effect may become much less pronounced for slender columns $(\lambda>60)$. In this case it may be neglected. 


\section{Acknowledgement}

The authors acknowledge the financial support from the state budget by the Slovenian Research Agency (project No. Z2-2031). In addition, the authors would also like to thank Mrs. Romana Hudin for a detailed language review of this paper.

\section{References}

[1] Adam, C., Heuer, R., Jeschko, A., 1997. Flexural vibrations of elastic composite beams with interlayer slip. Acta Mechanica 125 17-30.

[2] Dall'Asta, A., Zona, A., 2004. Comparison and validation of displacement and mixed elements for the non-linear analysis of continuous composite beams. Computers and Structures 82(23-26) 2117-2130.

[3] Battini, J.M., Nguyen, Q.H., Hjiaj, M., 2009. Non-linear finite element analysis of composite beams with interlayer slips. Computers and Structures $87904-912$.

[4] Čas, B., Saje, M., Planinc, I., 2004. Non-linear finite element analysis of composite planar frames with an interlayer slip. Computers and Structures 82 1901-1912.

[5] Čas, B., Bratina, S., Saje, M., Planinc, I., 2004. Non-linear analysis of composite steel-concrete beams with incomplete interaction. Steel and Composite Structures 4(6) 489-507.

[6] Čas, B., Saje, M., Planinc, I., 2007. Buckling of layered wood columns. Advances in Engineering Software 38 586-597.

[7] Chen, W.Q., Wu, Y.F., Xu, R.Q, 2007. State space formulation for composite beam-columns with partial interaction. Composites Science and Technology 67 2500-2512. 
[8] Xu, R.Q, Wu, Y.F., 2009. Analytical study of beams strengthened by adhesively bonded reinforcement with variable properties using state space method. Composites Science and Technology 69 1912-1918.

[9] Foraboschi, P., 2009. Analytical solution of two-layer beam taking into account nonlinear interlayer slip. Journal of Engineering Mechanics 135(10) $1129-1146$.

[10] Silva, A.R., Sousa, J.B.M., 2009. A family of interface elements for the analysis of composite beams with interlayer slip. Finite Elements in Analysis and Design 45(5) 305-314.

[11] Heuer, R., Adam, C., 2000. Piezoelectric vibrations of composite beams with interlayer slip. Acta Mechanica 140 247-263.

[12] Heuer, R., 2004. Equivalence of the analyses of sandwich beams with or without interlayer slip. Mechanics of Advanced Materials and Structures $11425-432$.

[13] Challamel, N., 2009. On lateral-torsional vibrations of elastic composite beams with interlayer slip. Journal of Sound and Vibration 325(4-5) $1012-1022$.

[14] Ranzi, G., Bradford, M.A., 2007a. Direct stiffness analysis of a composite beam-column element with partial interaction Computers and Structures 85(15-16) 1206-1214.

[15] Ranzi, G., Zona, A., 2007b. A steel-concrete composite beam model with partial interaction including the shear deformability of the steel component. Engineering Structures 29(11) 3026-3041.

[16] Ranzi, G., 2008. Locking problems in the partial interaction analysis of multi-layered composite beams. Engineering Structures 30(10) 29002911.

[17] Ranzi, G., Dall'Asta, A., Ragini, L., Zona, A., 2010. A geometric non- 
linear model for composite beams with partial interaction. Engineering Structures 32(5) 1384-1396.

[18] Schnabl, S., Planinc, I., Saje, M., Čas, B. and Turk, G., 2006. An analytical model of layered continuous beams with partial interaction. Structural Engineering and Mechanics 22 (3) 263-278.

[19] Schnabl, S., Saje, M., Turk, G. and Planinc, I., 2007a. Locking-free twolayer Timoshenko beam element with interlayer slip. Finite Elements in Analysis and Design 43 705-714.

[20] Schnabl, S., Saje, M., Turk, G. and Planinc, I., 2007b. Analytical solution of two-layer beam taking into account interlayer slip and shear deformation. Journal of Structural Engineering ASCE 133(6) 886-894.

[21] Planinc, I., Schnabl, S., Saje, M., Lopatič, J. and Čas, B., 2008. Numerical and experimental analysis of timber composite beams with interlayer slip. Engineering Structures 30(11) 2959-2969.

[22] Schnabl, S., Planinc, I., 2010. The influence of boundary conditions and axial deformability on buckling behavior of two-layer composite columns with interlayer slip. Engineering Structures 32(10) 3103-3111.

[23] Xu, R., Wu, Y., 2007. Two-dimensional analytical solutions of simply supported composite beams with interlayer slips. International Journal of Solids and Structures 44 165-175.

[24] Girhammar, U.A., Gopu, V.K.A., 1993. Composite beam-columns with interlayer slip-exact analysis. Journal of Structural Engineering 119(4) $1265-1282$.

[25] Girhammar, U.A., Pan, D.H., 2007. Exact static analysis of partially composite beams and beam-columns. International Journal of Mechanical Sciences 49(2) 239-255.

[26] Xu, R., Wu, Y., 2007. Free vibrations of the partial-interaction composite 
members with axial force. Journal of Sound and Vibration 299 1074-1093.

[27] Xu, R., Wu, Y., 2008. Free vibration and buckling of composite beams with interlayer slip by two-dimensional theory. Journal of Sound and Vibration 313 875-890.

[28] Rassam, H.Y, Goodman, J.R., 1970. Buckling behaviour of layered wood columns. Wood Science 2(4) 238-246.

[29] Kryžanowski, A., Schnabl, S., Turk, G., Planinc, I., 2009. Exact slipbuckling analysis of two-layer composite columns. International Journal of Solids and Structures 46 2929-2938.

[30] Ziegler, H., 1982. Arguments For and Against Engesser's Buckling Formulas. Ingenieur-Archiv 52 105-113.

[31] Reissner, E., 1982. Some Remarks on the Problem of Column Buckling. Ingenieur-Archiv 52 115-119.

[32] Wang, C.M., Kitipornchai, S., Al-Bermani, F.G., 1991. Buckling of columns: allowance for axial shortening. International Journal of Mechanical Sciences 33(8) 613-622.

[33] Banerjee, J.R., Williams, F.W., 1994. The effect of shear deformation on the critical buckling of columns. Journal of Sound and Vibration 174(5) 607-616.

[34] Timoshenko, S.P, Gere, J.M., 1961. Theory of Elastic Stability, McGrawHill Book Company, 2nd Ed. 1961.

[35] Bažant, ZP., Cedolin, L., 2003. Stability of Structures: Elastic, Inelastic, Fracture, and Damage Theories, Courier Dover Publications, New York, 1st Ed. 2003.

[36] Bažant, ZP., Beghini, A., 2004. Sandwich buckling formulas and applicability of standard computational algorithm for finite strain. Composites: Part B 35 573-581. 
[37] Bažant, ZP., Beghini, A., 2006. Stability and strain of homogenized structures soft in shear: Sandwich or fiber composites, and layered bodies. International Journal of Solids and Structures 43 1571-1593.

[38] Attard, MM., Hunt, GW., 2008. Sandwich column buckling - A hyperelastic formulation. International Journal of Solids and Structures 455540 5555.

[39] Kardomateas, GA., Dancila, DS., 1997. Buckling of moderately thick orthotropic columns: comparison of an elasticity solution with the Euler and Engesser/Haringx/Timoshenko formulae. International Journal of Solids and Structures 34(3) 341-357.

[40] Blaauwendraad, J., 2010. Shear in Structural Stability: On the EngesserHaringx Discord. Journal of Applied Mechanics 77(3) 031005 (8 pages) doi:10.1115/1.3197142.

[41] Engesser, F., 1891. Die Knickfestigkeit gerader Stabe. Zentralblatt der Bauverwaltung 11 483-486 [in Germain].

[42] Haringx, JA., 1942. On the buckling and the lateral rigidity of helical compression springs. Proceedings of the section of sciences of the Koninklijke Nederlandse Academie van Wetenschappen, Royal Academy of Sciences in the Netherlans 45 pp. 533.

[43] Xu, R., Wu, Y., 2007. Static, dynamic, and buckling analysis of partial interaction composite members using Timoshenko's beam theory. International Journal of Mechanical Sciences 49(10) 1139-1155.

[44] Krawczyk, P., Frey, F., Zielinski, A.P., 2007. Large deflections of laminated beams with interlayer slips: Part 1: model development. Engineering Computations 24(1) 17-32.

[45] Krawczyk, P., Rebora, B., 2007. Large deflections of laminated beams with interlayer slips: Part 2: finite element development. Engineering 
Computations 24(1) 33-51.

[46] Vratanar, B., Saje, M., 1999. A consistent equilibrium in a cross-section of an elastic-plastic beam. International Journal of Solids and Structures $36311-337$.

[47] Reissner, E., 1972. On one-dimensional finite-strain beam theory: The plane problem. Journal of Applied Mechanics and Physics (ZAMP) 23 $795-804$.

[48] Keller, H.B., 1970. Nonlinear bifurcation. Journal of Differential Equations $7417-434$.

[49] Planinc, I., Saje, M., 1999. A quadratically convergent algorithm for the computation of stability points: The application of the determinant of the tangent stiffness matrix. Computer Methods in Applied Mechanics and Engineering 169 89-105.

[50] Cowper, G.R., 1966. The shear coefficient in Timoshenko's beam theory. Journal of Applied Mechanics 33(2) 335-340.

[51] Flajs, R., Saje, M., Zakrajšek, E., 2003. On the existence and uniqueness of the generalized solution of the Reissner's elastica. Mathematics and Mechanics of Solids 8 3-19.

[52] Hartmann, F., 1985. The Mathematical Foundation of Structural Mechanics. Springer-Verlag Berlin and Heidelberg GmbH \& Co.K.

[53] Hirsch, MW., Smale, S. Differential equations, dynamical systems, and linear algebra, Academic Press, New York; 1974.

[54] Perko L. Differential equations and dynamical systems, Third Edition, Springer-Verlag, New York; 2001. 